\title{
$\$$ Research Square \\ Beneficial Effects of Liposome Containing Arthrocen (ROCEN)) on Atopic Dermatitis in Mice
}

\section{Ramin Goudarzi}

Division of Research and Development, Pharmin USA, LLC, San Jose, California, United States of America

\section{Maryam Eskandarynasab}

Tehran University of Medical Sciences

Ahad Muhammadnejad

Tehran University of Medical Sciences

Ahmad Reza Dehpour

Tehran University of Medical Sciences

Alireza Partoazar ( $\sim$ partoazar@yahoo.com )

Tehran University of Medical Sciences

\section{Research Article}

Keywords: Atopic dermatitis, avocado and soybean, Oxazolone, Eczema, IL-8, TNF-a

Posted Date: January 18th, 2021

DOl: https://doi.org/10.21203/rs.3.rs-143177/v1

License: (c) (i) This work is licensed under a Creative Commons Attribution 4.0 International License.

Read Full License 
Title:

\section{Beneficial effects of liposome containing arthrocen (ROCEN) on atopic} dermatitis in mice

\section{Author names and affiliations:}

Ramin Goudarzi $^{1}$ (Pharm D), Maryam Eskandarynasab ${ }^{2}$ (MS), Ahad Muhammadnejad ${ }^{3}$ (PhD), Ahmad Reza Dehpour ${ }^{2,4}$ (Pharm D, PhD), Alireza Partoazar ${ }^{2,4}(\mathrm{PhD})$

1. Division of Research and Development, Pharmin USA, LLC, San Jose, California, United States of America

2. Department of Pharmacology, School of Medicine, Tehran University of Medical Sciences, Tehran, Iran.

3. Cancer Biology Research Center, Cancer Institute of Iran, Tehran University of Medical Sciences, Tehran, Iran.

4. Experimental Medicine Research Center, Tehran University of Medical Sciences, Tehran, Iran

\section{Corresponding author:}

Alireza Partoazar, Ph.D., Assistant professor of Medical Nanotechnology.

Experimental Medicine Research Center, Tehran University of Medical Sciences, Tehran, Iran. P.O. Box: 13145-784, Tehran, Iran.

Tel/Fax: +98-21-66402569;

E-mails: partoazar@tums.ac.ir, partaozar@yahoo.com 


\begin{abstract}
Objective: Atopic dermatitis (AD) is a chronic inflammatory skin disease caused mainly by the immune stimulus. The current study aimed to investigate the effects of liposome containing arthrocen (ROCEN) and its comparison with betamethasone (Beta) on mice subjected to AD. Methods: First of all, the risk assessment of ROCEN sensitization was done, then mice were subjected to oxazolone (Oxa) for chronic AD induction and treatment. Scratching and wiping behaviors related to dermatitis were evaluated in animals treated topically with ROCEN. The histological and immunohistochemistry analysis of interleukin-8 (IL-8) and tumor necrosis factor- $\alpha($ TNF- $\alpha)$ were conducted to the dorsal skin of treated rats. Results: The results showed that cutaneous administration of ROCEN on sensitized mice for 5 weeks, alleviated significantly scratching and wiping symptoms, erythema, scaling, and edema in animals' skin. Moreover, histological indices showed that ROCEN reduced effectively leucocyte infiltration and improved skin healing parameters in AD mice. Immunohistochemically markers of IL- 8 and TNF- $\alpha$ were hindered significantly by ROCEN in dermal tissues of mice. Conclusion: ROCEN potentiated alleviation of the $\mathrm{AD}$ symptoms rather than betamethasone drug in an experimental model.
\end{abstract}

Keywords: Atopic dermatitis, avocado and soybean, Oxazolone, Eczema, IL-8, TNF- $\alpha$. 


\section{Introduction}

$\mathrm{AD}$ is an increasingly prevalent chronic inflammatory skin disease worldwide [1]. The most common symptoms of AD-like hand eczema are intense itching, a typical distribution of mild to severe rash, edema, hemorrhage, and erosion [2]. AD is a multifactorial disease associated with a variety of immunological mechanisms that environmental and even neuropsychological factors can play role in the development of this disease [3-5].

One of the characteristic features of $\mathrm{AD}$ is the involvement of various inflammatory cells including lymphocytes, eosinophil, neutrophils, with a predominance $\mathrm{Th}_{2}$ cell response [6,7] An allergen exposure can stimulate keratinocytes and release cytokines like TNF-a, resulting in the excitation of proinflammatory cytokines production including IL-1b, IL-6, and IL-8 from other keratinocytes and dermal cells [7]. It can be directed to the allergic phase via recruitment and activation of leukocytes and dendritic cells and presenting the allergen to specific T-cells. It is also indicated that IL-8 cytokine production by $\mathrm{Th}_{2}$ cells activated by allergic contact response can contribute to activation and regulation of various immune cells in inflamed tissues $[7,8]$.

Chronic AD, eczema, is mostly treated with corticosteroids like Beta [9] while their long-term usage can bring serious side effects including hyperglycemia and dermal and epidermal injuries [10]. Therefore, new formulation and drugs are always the interest of modern medicine to improve the life quality of $\mathrm{AD}$ patients.

Arthrocen (ASU), an oil extract of avocado and soybean, has shown that it downregulates inflammatory mediators such as TNF $\alpha$, IL8, and $\mathrm{PE}_{2}$ while increases the expression of transforming growth factor-beta (TGF- $\beta$ ), production of collagen, and aggrecan in connective tissue $[11,12]$. Therefore, evidence reports suggest that topical ASU may regulate inflammatory cells and cytokines associated with AD symptoms and improve tissue impairment due to eczema [13].

However, because of the very low water solubility of Arthrocen, the use of pharmaceutical carriers such as liposomes is recommended for effective skin delivery of lipophilic molecules of ASU [14-16]. Liposome carriers not only are versatile tools in drug delivery but also have anti-oxidative, anti-inflammatory, and wound repair properties [17-19]. Recently, we have used the topical formulation of 
liposomal ASU to enhance the drug efficacy in wound healing, inflammation reduction, and pain alleviation in animal models $[13,16]$. In the study by Goudarzi et al., ROCEN formulation has caused potentially TGF- $\beta 1$ production in burnt tissues of rats resulting in wound healing acceleration and thermal pain alleviation with a long-lasting effect [13]. Hence, we also aimed to investigate the effects of the topical application of ROCEN and its comparison with Beta drug on AD mice model.

\section{Materials and methods}

\section{Drug preparation}

Liposomal formulation of ASU was prepared according to our recent study.[13] Briefly, lecithin (10\% w/v), PG (15\% v/v), cholesterol (1\% w/v), and ASU $(2 \% \mathrm{w} / \mathrm{v})$ were dissolved in ethanol. Then phosphate buffer saline was added to the mixture at $40^{\circ} \mathrm{C}$ and under stirring condition $(700 \mathrm{rpm})$. Eventually, the suspension was homogenized with mild power for $5 \mathrm{~min}$ to obtain ROCEN formulation. Oxazolone (Oxa) was obtained from Sigma-Aldrich, (USA) Arthrocen manufactured by Pharmin USA, LLC (USA) and Betamethasone \%0.1 was prepared from Sobhan Daru Pharmaceutical Company (Iran).

\section{Animal}

The 6-8 weeks female BALB/c mice (mean weight $30 \pm 2 \mathrm{~g}$ ) were procured from Tehran University of Medical Sciences (Tehran, Iran). The animals were placed under controlled environmental conditions at $23 \pm 1{ }^{\circ} \mathrm{C}$ with $50 \%$ humidity and $12 \mathrm{~h}$ dark/light cycles. The animals were subjected to acclimatization for at least 1 week before the experiment.

\section{Safety evaluation of ROCEN}

In this study, a primary delayed-type contact hypersensitivity test, MEST, was considered for evaluation of possible allergic contact dermatitis due to ROCEN application. Briefly, mice were divided into 3 groups consisted of 10 rats including control, ROCEN, formaldehyde (positive control). The test substance was judged to be a nonirritant agent before MEST and then the test was carried out according to a standard protocol that it has been depicted briefly in Figure 1. A positive sensitization response is brought up to have happened if the one or more ear test of mice was at least $20 \%$ thicker than the control ear [20].

\section{Induction of dermatitis and treatment}

AD was induced in mice according to the Goindi et al. method [21]. Firstly, female BALB/c mice were anesthetized with ketamine $(50 \mathrm{mg} / \mathrm{kg})$ and xylazine (10 
$\mathrm{mg} / \mathrm{kg}$ ) and the hair on the upper back of each animal was shaved one day before the experiments. AD was induced by topical application of $10 \mu \mathrm{L}$ Oxa $(5 \% \mathrm{w} / \mathrm{v}$ in ethanol) on the shaved dorsal skin daily for one week. Then, the same experiments were followed daily by gently rubbing of $60 \mu \mathrm{L}$ Oxa $(0.5 \% \mathrm{w} / \mathrm{v}$ in ethanol) with a frequency of $30 \times$ per min on the dorsal skin at the four weeks. 90 min after Oxa application, drug was administered topically by rubbing with a frequency of $50 \times$ per min on the animals' back of treated groups. In the control group, only $60 \mu \mathrm{L}$ ethanol (without Oxa) was applied to the dorsum of mice.

\section{Experimental design}

The mice were randomly divided into the four groups with 6 animals in each experiment and defined as follows: group: vehicel, Oxazolone (Oxa) group: Oxa $60 \mu \mathrm{g} /$ day + Water $100 \mu \mathrm{g} /$ day, ROCEN group: Oxa $60 \mu \mathrm{g} /$ day + ROCEN $100 \mu \mathrm{g} /$ day, Beta group: Oxa $60 \mu \mathrm{g} /$ day + Beta $1 \%, 100 \mu \mathrm{g} /$ day. In all experimental days (0-35), evaluation of behavior-related skin dermatitis was done according to the below protocols. One day after the last dose of the drug (36th day), animals were euthanized with $\mathrm{CO}_{2}$ and then their dorsal skins separated for histological analysis. A brief description of the experimental is individual in Figure 2.

\section{Evaluation of skin severity}

The severity of AD on the dorsal skin was evaluated once a week according to four symptoms of erythema, scarring/dryness, edema, and excoriation/erosion. The symptom of erythema was scored as 0 (none), 1 (very slight (light pink )), 2 ( well-defined (dark pink)), 3 (Moderate to severe (light red)), 4 (Severe (dark red)). The other relative symptoms were scored by numbers of 0 (none), 1 (mild), 2 (moderate), 3 (severe). An experimental score was defined as skin severity score achieved by the sum of the relative data of dermatitis symptoms for each experiment [22].

\section{Measurement of scratching/wiping behavior}

Mice were placed individually in the acrylic cages with the four cells in dimensions of $15 \mathrm{~cm} \times 10 \mathrm{~cm} \times 10 \mathrm{~cm}$. The small openings were created in each cell to allow air circulation. The camera recorder was embedded in front of the cages to record animals' behavior. The adaptation of mice to the experimental conditions was done by handling, restraining, and placing them in containers several times before the experiments began at each experimental day. On the days of experiment (7-1428-35), 90 min after drug application, the animals' behavior was recorded for $20 \mathrm{~min}$ while non-experimenters present in the observation room. Scratching, grooming, 
and licking behaviors were assessed according to the frequency of each behavior during 20 min experiment which counted from video records [23].

\section{Histopathology and immunohistochemistry}

Tissue samples were taken from dermatitis areas of mice dorsum one day after the treatment. Skin samples were fixed in $10 \%$ (v/v) formalin buffer with PBS and then dehydrated and embedded in paraffin. The section of samples was prepared with $5 \mu \mathrm{m}$ thickness and stained with hematoxylin and eosin for histopathology analyses. An expert pathologist assessed as blindness the sections for epithelial thickness, collagen deposition, angiogenesis, leukocyte infiltration, mononuclear cells (MCs), lymphocytes (Lymphs)/Plasma cells (PCs) using a light photomicroscope. The tissue slides were also subjected to immunohistochemical assay of TNF- $\alpha$ (orb39299, biorbyt, Cambridge (United Kingdom)), IL-8 (orb39299, biorbyt, Cambridge (United Kingdom)) using commercially available antibodies according to the manufacturers' instructions, and being analyzed by pathologist.[24]

\section{Statistical analysis}

Statistical analysis of data was performed by one-way analysis of variance (ANOVA) to compare the significant differences among each group. $\mathrm{P}<0.05$ was considered as statistically significant.

\section{Results}

\section{Safety of ROCEN}

MEST was carried out to further assess the sensitization potential in ROCEN treatment and the results were shown in Figure 3ABC. In the positive control group, topical application of formaldehyde caused a significant increase in ear thickness and redness region of mice $(\mathrm{p}<0.0001)$. It was indicated that ROCEN did not cause any sensitivities in the ear thickness and redness region of mice.

\section{Skin severity reduction by ROCEN}

After the repeated application of Oxa, skin dryness occurred first, followed by mild erythema and edema. Finally, the skin became thick and severe erythema, edema, and scarring were observed, and these symptoms could not be detected in the control group (Figure 4A). As shown in Figure 4B, the dermatitis scores of the Oxa group increased rapidly and became significant every week after the first elicitation compared to the control group $(\mathrm{p}<0.0001)$. However, in the ROCEN Group, skin lesions were minimally observed compared to Oxa and beta groups ( $p$ 
$<0.05)$. The application of Beta as a standard drug caused significant improvement of dermatitis only on days $28(\mathrm{p}<0.05)$ and $35(\mathrm{p}<0.01)$ (Figure $4 \mathrm{~B})$.

\section{Itching control by ROCEN}

The scratching number was calculated at days of 7, 14, 28, and 35 for $20 \mathrm{~min}$. Oxa group was showed a significant increase of scratching, grooming, and licking events 30 min after the Oxa application compared to the c group at all days $(\mathrm{p}<0.05)$ (Table 1). The scratching and the wiping scores in the ROCEN treatment were significantly lower $(\mathrm{p}<0.05)$ than the Oxa group at all-time intervals. The remains of the analyzes are shown in detail in Table 1. These results suggest ROCEN improve the effects of eczema even better than Beta group (Table 1).

\section{Histological and immunohistochemical analysis}

Histological changes in mice dorsal skins were compared between Oxa and treated groups on the $36^{\text {th }}$ day of the experiment. lesional skin in Oxa group showed a significant $(\mathrm{p}<0.05)$ epithelial thickness, collagen deposition, angiogenesis, and leukocyte infiltration (Table $2 \&$ Figure 5A-I). The histological parameters were significantly $(\mathrm{p}<0.05)$ improved by ROCEN via the increased epithelial thickness reduced collagen deposition, and decreased angiogenesis in comparison with the untreated Oxa group. Furthermore, the infiltration of inflammatory cells such as MCs, lymphocytes, eosinophil, and neutrophil was significantly $(\mathrm{p}<0.05)$ reduced by ROCEN (Figure 5C) and the ROCEN group works better than the beta group. The number of basophils did not show any significant differences among the groups (Figure 5A - II). Immunohistochemical staining revealed significantly $(\mathrm{p}<0.001)$ overproduction of IL- 8 and TNF- $\alpha$ in the sensitized dermis after topical application of Oxa compared to the control as depicted in Figure 6A-C. Topical ROCEN application decreased significantly $(\mathrm{p}<0.05)$ IL- 8 and TNF- $\alpha$ staining compared with Oxa.

\section{Discussion}

$\mathrm{AD}$ or eczema as a common chronic inflammatory skin disorder is associated with chronic itch, pruritus, inflammation, and cell proliferation [1]. Treatment of patients' $\mathrm{AD}$ with systemic oral corticosteroids or even topical corticosteroids like Beta may be potentially at risk of side effects of the drug $[10,25]$. In this study, we used topical Beta as a mainstay drug in the treatment of atopic eczema for comparison with ROCEN as a new anti-AD formulation on a murine model. 
Topical application of ROCEN hydrogel moisturize the skin and also to be its safe components without irritability, can be reasonable for its long term application in allergic dermatitis. ROCEN has been prepared from natural oil [11] and lecithin in the liposomal structure that is well known as drug supplementation without any adverse effect in pharmacy [13]. Treatment of AD with ROCEN not only has had anti-inflammatory and analgesic effects in experimental reports but also due to its permeability property may play role in barrier homeostasis of the skin $[13,16]$.

In the current study, treatment with topical ROCEN was associated with the improvement of all important dermatitis symptoms and hindering the itching and wiping behaviors in mice subjected to eczema. Itching is the major symptom of inflammatory $\mathrm{AD}$ that impairs the patients' life quality [26, 27]. Itching stimulates scratch reflex and increases the desire to scratch, resulting in exacerbation of the skin lesions, secondary infections, and sleep disturbances in the patient. Therefore attenuation of itching is believed to be one of the fundamental approaches in controlling skin lesion progression in an eczematous state [28].

Histopathology of eczematous lesions is characterized by epidermal hyperplasia and dermal inflammatory cell infiltration with increased numbers of monocyte, macrophages, mast cell, basophil, eosinophil [29, 30], and neutrophil in an early inflammatory reaction [31].

Angiogenesis occurs physiologically in the wound healing and during inflammatory diseases [32] while mast cells in AD lesions may stimulate angiogenesis via the release of proangiogenic factors [33]. Besides, fibrocystic accumulation in the skin fibrogenesis can lead to the production of cytokines that induce collagen deposition in the lesion site [34-36]. It has been indicated that suppress of fibrogenesis causes reduction of proangiogenic mediators resulting in decreasing angiogenesis and activation of T cells [37].

In this study, ROCEN daily application modulated significantly angiogenesis and collagen deposition and reduced leucocyte infiltration such as eosinophil rather than Beta cream in skin tissue of $\mathrm{AD}$ mice.

In our study, TNF- $\alpha$ [38] and IL-8 [1, 39] as proinflammatory cytokines involved in allergic contact dermatitis were evaluated histochemically after 36 days of topical treatment with ROCEN. It has been proposed that IL-8 is a non-specific mediator with mitogenic activity in keratinocytes that induced inflammation or immunogenic after stimulation with contact sensitizers and irritants [39]. Moreover, 
the upregulation of TNF- $\alpha$ along with other inflammatory cytokines contributes to the changes in epidermal abnormality and skin barrier dysfunctionality. This results in thickened skin and scale formation [1, 40]. Our immunohistochemically data indicated that both TNF- $\alpha$ and IL- 8 have downregulated by ROCEN in lesion tissues related to AD. Therefore, according to the results, it can be suggested that improvement of tissue indices and reduction of inflammation in dermatitis by ROCEN may be associated with the down-regulation of IL-8 and TNF-a cytokine factors.

\section{Conclusion}

This study supported evidence of the therapeutic benefits of topical ROCEN even better than Beta in control of AD. Current results suggest that ROCEN can reduce tissue damage, dermatitis symptoms like pruritus, and downregulation of inflammatory cytokines associated with a contact stimulus. Topical ROCEN may be applicable in the clinic instead of current AD therapeutics to minimize side effects.

\section{Declarations}

\section{Ethics approval and consent to participate}

All animal experiments were approved by the Ethics Committee of Tehran University of Medical Sciences in agreement with the standards for the use of laboratory animals (No. 1398.226). No data concerning clinical studies or involving human subjects in this study.

\section{Consent for publication}

All authors agree to publish the work in this journal.

\section{Availability of data and materials}

All data are available in this paper.

Declaration of interest: No conflict of interest exists concerning the submitted manuscript. It is confirmed that all methods have been performed in accordance with the relevant guidelines and regulations.

\section{Funding}

This work was funded by Tehran University of Medical Sciences \& Health Services (No. 98-01-158-41384).

\section{Authors' contributions}

1. Ramin Goudarzi: Conceptualization, Writing, and Reviewing.

2. Maryam Eskandarynasab: Animal study, methodology.

3. Ahad Muhammadnejad: Histopathology evaluation, Data curation.

4. Ahmad Reza Dehpour: Data validation, Pharmacologist.

5. Alireza Partoazar: Supervision, Drug preparation, Resources. 


\section{References}

1. Lee GR, Maarouf M, Hendricks AK, Lee DE, Shi VY. Current and emerging therapies for hand eczema. Dermatol Ther. 2019;32(3):e12840.

2. Coenraads PJ. Hand eczema. N Engl J Med. 2012;367(19):1829-1837.

3. Pastore S, Mascia F, Giustizieri ML, Giannetti A, Girolomoni G. Pathogenetic mechanisms of atopic dermatitis. Archivum immunologiae et therapiae experimentalis. 2000;48(6):497-504.

4. Leung DY. Atopic dermatitis: new insights and opportunities for therapeutic intervention. Journal of Allergy and Clinical Immunology. 2000;105(5):860-876.

5. Akdis CA, Akdis M, Trautmann A, Blaser K. Immune regulation in atopic dermatitis. Current opinion in immunology. 2000;12(6):641-646.

6. Kang JS, Lee K, Han S-B, et al. Induction of atopic eczema/dermatitis syndrome-like skin lesions by repeated topical application of a crude extract of Dermatophagoides pteronyssinus in NC/Nga mice. International immunopharmacology. 2006;6(10):1616-1622.

7. Peiser M, Tralau T, Heidler J, et al. Allergic contact dermatitis: epidemiology, molecular mechanisms, in vitro methods and regulatory aspects. Current knowledge assembled at an international workshop at BfR, Germany. Cell Mol Life Sci. 2012;69(5):763-781.

8. Sticherling M, Bornscheuer E, Schroder JM, Christophers E. Immunohistochemical studies on NAP1/IL-8 in contact eczema and atopic dermatitis. Arch Dermatol Res. 1992;284(2):82-85.

9. Berke R, Singh A, Guralnick M. Atopic dermatitis: an overview. American family physician. 2012;86(1):35-42.

10. Hengge UR, Ruzicka T, Schwartz RA, Cork MJ. Adverse effects of topical glucocorticosteroids. J Am Acad Dermatol. 2006;54(1):1-15; quiz 16-18.

11. Henrotin YE, Deberg MA, Crielaard J-M, Piccardi N, Msika P, Sanchez C. Avocado/soybean unsaponifiables prevent the inhibitory effect of osteoarthritic subchondral osteoblasts on aggrecan and type II collagen synthesis by chondrocytes. The Journal of rheumatology. 2006;33(8):1668-1678.

12. Au R, Al-Talib T, Au A, Phan P, Frondoza C. Avocado soybean unsaponifiables (ASU) suppress TNF$\alpha$, IL-1 $\beta$, COX-2, iNOS gene expression, and prostaglandin E2 and nitric oxide production in articular chondrocytes and monocyte/macrophages. Osteoarthritis and cartilage. 2007;15(11):1249-1255.

13. Goudarzi R, Nasab ME, Saffari PM, Zamanian G, Park CD, Partoazar A. Evaluation of ROCEN on Burn Wound Healing and Thermal Pain: Transforming Growth Factor-beta1 Activation. Int J Low Extrem Wounds. 2020:1534734620915327.

14. Kianvash N, Bahador A, Pourhajibagher $\mathrm{M}$, et al. Evaluation of propylene glycol nanoliposomes containing curcumin on burn wound model in rat: biocompatibility, wound healing, and antibacterial effects. Drug Deliv Transl Res. 2017;7(5):654-663.

15. Partoazar A, Kianvash N, Darvishi MH, Nasoohi S, Rezayat SM, Bahador A. Ethosomal Curcumin Promoted Wound Healing and Reduced Bacterial Flora in Second Degree Burn in Rat. Drug Res (Stuttg). 2016;66(12):660-665.

16. Goudarzi R, Amini S, Dehpour AR, Partoazar A. Estimation of Anti-inflammatory and Analgesic Effects of Topical NANOCEN (Nanoliposomal Arthrocen) on Mice. AAPS PharmSciTech. 24 2019;20(6):233.

17. Nasab ME, Takzaree N, Saffari PM, Partoazar A. In vitro antioxidant activity and in vivo woundhealing effect of lecithin liposomes: a comparative study. J Comp Eff Res. Jun 2019;8(8):633-643.

18. Saffari PM, Alijanpour S, Takzaree N, et al. Metformin loaded phosphatidylserine nanoliposomes improve memory deficit and reduce neuroinflammation in streptozotocin-induced Alzheimer's disease model. Life Sci. 28 2020;255:117861.

19. Zamanian G, Partoazar A, Tavangar SM, et al. Effect of phosphatidylserine on cirrhosis-induced hepatic encephalopathy: Response to acute endotoxemia in cirrhotic rats. Life Sci. 15 2020;253:117606.

20. Thorne PS, Hawk C, Kaliszewski SD, Guiney PD. The noninvasive mouse ear swelling assay: I. Refinements for detecting weak contact sensitizers. Fundamental and Applied Toxicology. 1991;17(4):790-806.

21. Goindi S, Kumar G, Kaur A. Novel flexible vesicles based topical formulation of levocetirizine: in vivo evaluation using oxazolone-induced atopic dermatitis in murine model. Journal of liposome research. 2014;24(3):249-257. 
22. Matsuda H, Watanabe N, Geba GP, et al. Development of atopic dermatitis-like skin lesion with IgE hyperproduction in NC/Nga mice. International immunology. 1997;9(3):461-466.

23. Shimada SG, LaMotte RH. Behavioral differentiation between itch and pain in mouse. Pain. 2008;139(3):681-687.

24. Sheu MY, Fowler AJ, Kao J, et al. Topical peroxisome proliferator activated receptor- $\alpha$ activators reduce inflammation in irritant and allergic contact dermatitis models. Journal of Investigative Dermatology. 2002;118(1):94-101.

25. Diepgen TL, Agner T, Aberer W, et al. Management of chronic hand eczema. Contact Dermatitis. 2007;57(4):203-210.

26. Koblenzer CS. Itching and the atopic skin. Journal of allergy and clinical immunology. 1999;104(3):S109-S113.

27. Bender BG, Leung SB, Leung DY. Actigraphy assessment of sleep disturbance in patients with atopic dermatitis: an objective life quality measure. Journal of allergy and clinical immunology. 2003;111(3):598-602.

28. Wahlgren C-F. Itch and atopic dermatitis: clinical and experimental studies. Acta dermatovenereologica Supplementum. 1991;165:1-53.

29. Straumann A, Simon HU. The physiological and pathophysiological roles of eosinophils in the gastrointestinal tract. Allergy. 2004;59(1):15-25.

30. Mihm MC, Jr., Soter NA, Dvorak HF, Austen KF. The structure of normal skin and the morphology of atopic eczema. J Invest Dermatol. 1976;67(3):305-312.

31. Ott NL, Gleich GJ, Peterson EA, Fujisawa T, Sur S, Leiferman KM. Assessment of eosinophil and neutrophil participation in atopic dermatitis: comparison with the IgE-mediated late-phase reaction. Journal of allergy and clinical immunology. 1994;94(1):120-128.

32. Ferrara N. Vascular endothelial growth factor: pathophysiology and clinical implications. Angiogenesis: CRC Press; 2006: 15-50.

33. Detoraki A, Granata F, Staibano S, Rossi F, Marone G, Genovese A. Angiogenesis and lymphangiogenesis in bronchial asthma. Allergy. 2010;65(8):946-958.

34. Quan TE, Cowper S, Wu S-P, Bockenstedt LK, Bucala R. Circulating fibrocytes: collagen-secreting cells of the peripheral blood. The international journal of biochemistry \& cell biology. 2004;36(4):598-606.

35. Schmidt M, Sun G, Stacey MA, Mori L, Mattoli S. Identification of circulating fibrocytes as precursors of bronchial myofibroblasts in asthma. The Journal of Immunology. 2003;171(1):380389.

36. Metz C. Fibrocytes: a unique cell population implicated in wound healing. Cellular and Molecular Life Sciences CMLS. 2003;60(7):1342-1350.

37. Chesney J, Bacher M, Bender A, Bucala R. The peripheral blood fibrocyte is a potent antigenpresenting cell capable of priming naive T cells in situ. Proceedings of the National Academy of Sciences. 1997;94(12):6307-6312.

38. Kiehl P, Falkenberg K, Vogelbruch M, Kapp A. Tissue eosinophilia in acute and chronic atopic dermatitis: a morphometric approach using quantitative image analysis of immunostaining. British Journal of Dermatology. 2001;145(5):720-729.

39. Mohamadzadeh M, Miiller M, Hultsch T, Enk A, Saloga J, Knop J. Enhanced expression of IL-8 in normal human keratinocytes and human keratinocyte cell line HaCaT in vitro after stimulation with contact sensitizers., tolerogens and irritants. Experimental dermatology. 1994;3(6):298-303.

40. Danso MO, Van Drongelen V, Mulder A, et al. TNF- $\alpha$ and Th2 cytokines induce atopic dermatitislike features on epidermal differentiation proteins and stratum corneum lipids in human skin equivalents. Journal of Investigative Dermatology. 2014;134(7):1941-1950. 
Table 1. Scratching/wiping frequency data in treated $\mathrm{AD}$ mice. Data are defined as the mean \pm SEM; $n=6$ for all groups. a,b,c,d: Oxa compared with control group. A,B,C,D: treated groups compared with Oxa group. 1,2,3,4: ROCEN compared with Beta group. Aa); p <0.05, $\mathrm{Bb}^{r} ; \mathrm{p}<0.01, \mathrm{Cc}^{r} ; \mathrm{p}<0.001, \mathrm{Dd}^{\kappa} ; \mathrm{p}<0.0001$.

\begin{tabular}{|c|c|c|c|c|c|}
\hline Behavior type & Date & Oxa & Sham & Rocen + Oxa & Beta + Oxa \\
\hline \multirow{4}{*}{$\begin{array}{l}\text { No. of scratching } \\
\text { (per } 20 \text { min) }\end{array}$} & $7^{\text {th }}$ day & $42.8 \pm 6.8^{\mathrm{C}}$ & $9.6 \pm 3.8$ & $14 \pm 4.3^{\mathrm{b}}$ & $18 \pm 0.3^{\mathrm{a}}$ \\
\hline & $14^{\text {th }}$ day & $18.2 \pm 4.1^{\text {B }}$ & $9 \pm 4.5$ & $10.5 \pm 3.5^{\mathrm{a}}$ & $13 \pm 3.2$ \\
\hline & $28^{\text {th }}$ day & $108 \pm 16.1^{\mathrm{D}}$ & $7.5 \pm 1$ & $29.6 \pm 6.1^{\mathrm{d}^{*}}$ & $54.25 \pm 18.5^{\mathrm{b}}$ \\
\hline & $35^{\text {th }}$ day & $113.6 \pm 14^{\mathbf{D}}$ & $10 \pm 3$ & $32.6 \pm 10.3^{\mathrm{d} 1}$ & $50.7 \pm 15.3^{\mathrm{c}}$ \\
\hline \multirow{4}{*}{$\begin{array}{l}\text { No. of grooming } \\
\text { (per } 20 \mathrm{~min} \text { ) }\end{array}$} & $7^{\text {th }}$ day & $29.8 \pm 8.8^{\mathbf{A}}$ & $9.6 \pm 3.8$ & $8.2 \pm 3.9^{\mathbf{b} 1}$ & $16.3 \pm 2.1^{\mathrm{a}}$ \\
\hline & $14^{\text {th }}$ day & $21.2 \pm 1.9^{\mathbf{A}}$ & $14 \pm 1.8$ & $18.4 \pm 2.7$ & $18 \pm 1.4$ \\
\hline & $28^{\text {th }}$ day & $67.4 \pm 6.5^{\mathrm{D}}$ & $6 \pm 7$ & $10.5 \pm 1.9^{\mathrm{d} 1}$ & $30.5 \pm 2.7^{\mathrm{d}}$ \\
\hline & $35^{\text {th }}$ day & $78 \pm 12.5^{\mathbf{D}}$ & $12.5 \pm 2.5$ & $53.6 \pm 10.3^{\mathrm{a}}$ & $39.7 \pm 8.2^{\mathbf{b}}$ \\
\hline \multirow{4}{*}{$\begin{array}{l}\text { Time of licking(s) } \\
\text { (per } 20 \text { min) }\end{array}$} & $7^{\text {th }}$ day & $341.8 \pm 7^{\mathrm{D}}$ & $74 \pm 12.1$ & $115 \pm 41.3^{\mathrm{d} 2}$ & $229.4 \pm 71.3$ \\
\hline & $14^{\text {th }}$ day & $174 \pm 29.5$ & $107 \pm 48.6$ & $129.6 \pm 25.1$ & $214.3 \pm 131$ \\
\hline & $28^{\text {th }}$ day & $294.6 \pm 39.2^{\mathrm{D}}$ & $34.3 \pm 4.5$ & $40.3 \pm 1.9^{\mathrm{d} 3}$ & $234.2 \pm 19.5^{\mathrm{a}}$ \\
\hline & $35^{\text {th }}$ day & $340 \pm 40.4^{\mathrm{D}}$ & $12.5 \pm 2.5$ & $58.1 \pm 22.3^{\mathrm{c}^{2}}$ & $229.5 \pm 8.5$ \\
\hline
\end{tabular}

Table 2: The dorsal skin histological changes in mice. a,b,c,d: Oxa compared with control group. A,B,C,D: treated groups compared with Oxa group. 1,2,3,4: ROCEN compared with Beta group. Aa1; $<<0.05$, Bb2; p <0.01, Cc3; p <0.001, Dd4; $<<0.0001$.

\begin{tabular}{|c|c|c|c|c|}
\hline Experiment & $\begin{array}{l}\text { Epithelial thickness } \\
\qquad(\mu \mathrm{m})\end{array}$ & $\begin{array}{c}\text { Collagen deposition } \\
\%\end{array}$ & $\begin{array}{c}\text { Angiogenesis } \\
\text { No./ mm }\end{array}$ & $\begin{array}{c}\text { Leucocyte infiltration } \\
\text { No./mm }\end{array}$ \\
\hline Oxa & $67.74 \pm 7.68^{\mathrm{C}}$ & $52.49 \pm 4.4^{\mathrm{B}}$ & $4.8 \pm 0.54^{\mathrm{A}}$ & $1250 \pm 85.63^{\mathrm{C}}$ \\
\hline Sham & $159.5 \pm 33.84$ & $37.01 \pm 3.98$ & $3.63 \pm 0.66$ & $913.33 \pm 76.88$ \\
\hline ROCEN+ Oxa & $139.8 \pm 12.42^{\mathrm{b}}$ & $34.11 \pm 3.74^{\mathrm{b}}$ & $3.8 \pm 0.23^{\mathrm{a}}$ & $806 \pm 51.92^{\mathrm{d} 2}$ \\
\hline Beta + Oxa & $107.77 \pm 9.77$ & $43.9 \pm 4.14$ & $6.05 \pm 1.1$ & $1045 \pm 51.85^{\mathrm{a}}$ \\
\hline
\end{tabular}




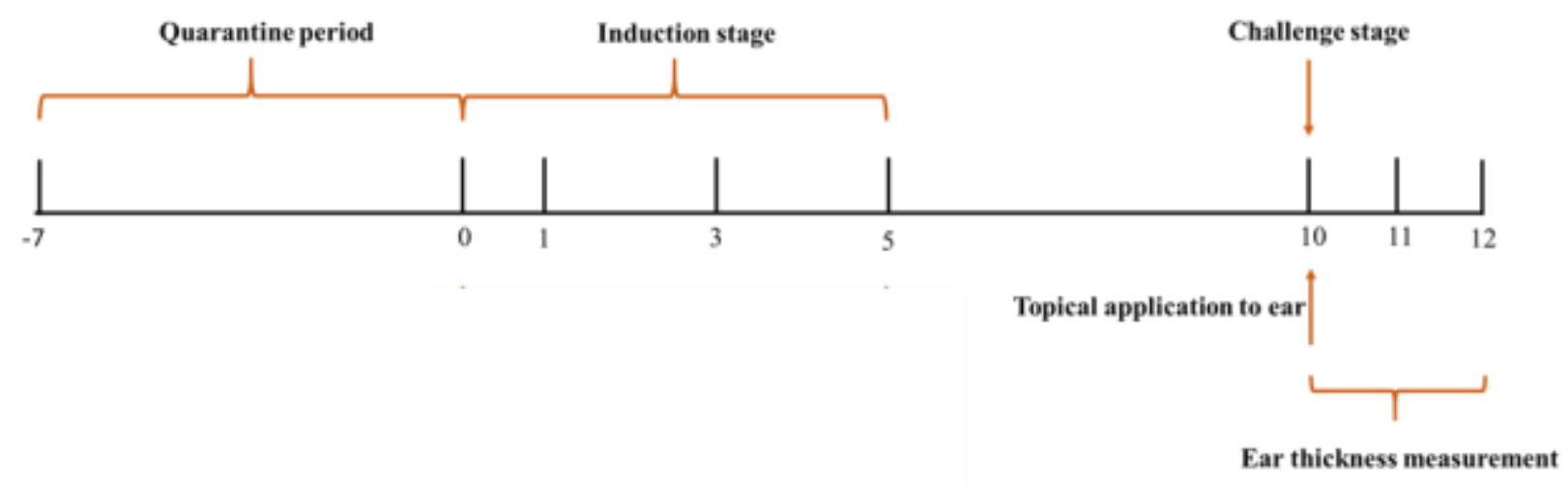

Figure. 1: The line chart of the MEST protocol for allergenicity assessment.

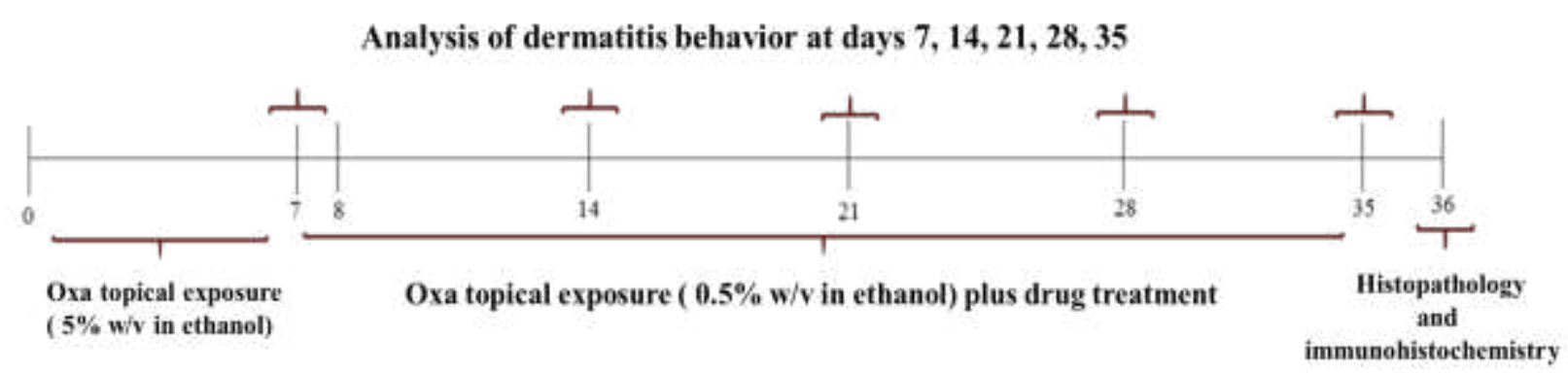

Figure 2: Summary of experimental dermatitis protocol. 


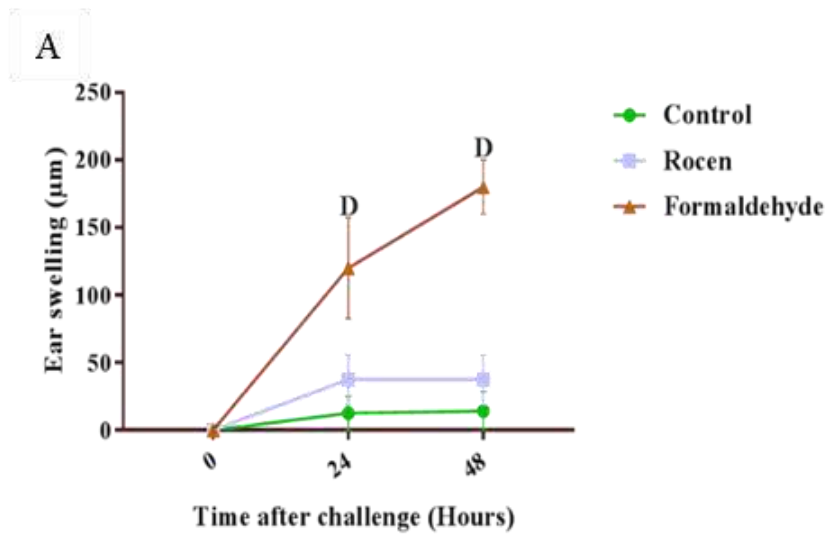

B

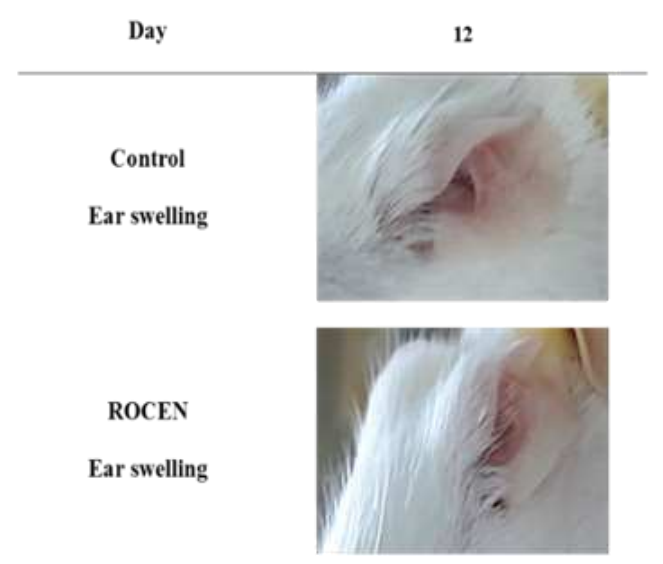

C

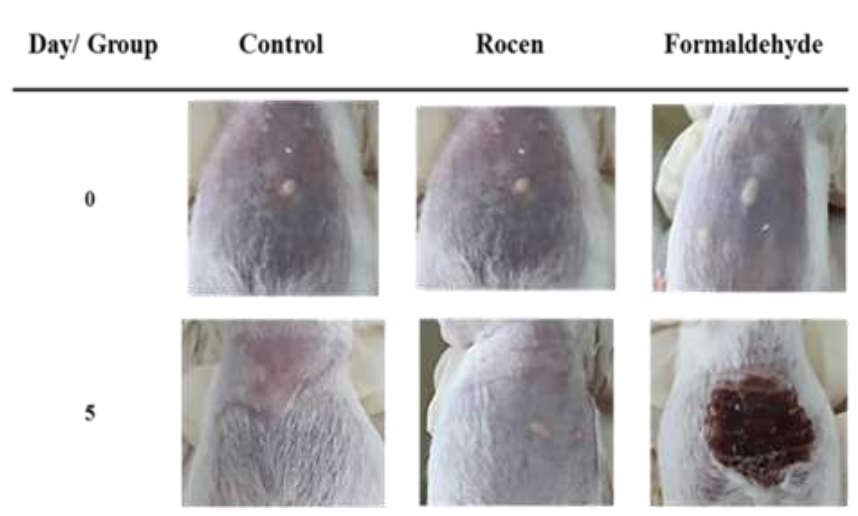

Formaldehyde

Ear swelling

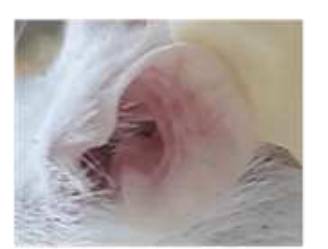

Figure 3: The demonstration of ROCEN sensitization evaluation using MEST. A. Swelling measurement of the left ear of the mice did not show any irritation via ROCEN application. $\mathrm{n}=10$ for all groups. D when treated groups compared with control group, (D; P-value < 0.0001). B. The representative mice ear shows a considerable ear redness in formaldehyde group (sensitized mice). C. The mice were shaved ventral abdomen on day 0 for induction of sensitization by applying two intradermal injections $(40 \mu \mathrm{l})$ of adjuvant and $100 \mu \mathrm{l}$ of water (control), ROCEN, formaldehyde (as dermatitis lesion) were applied topically by rubbing gently. 

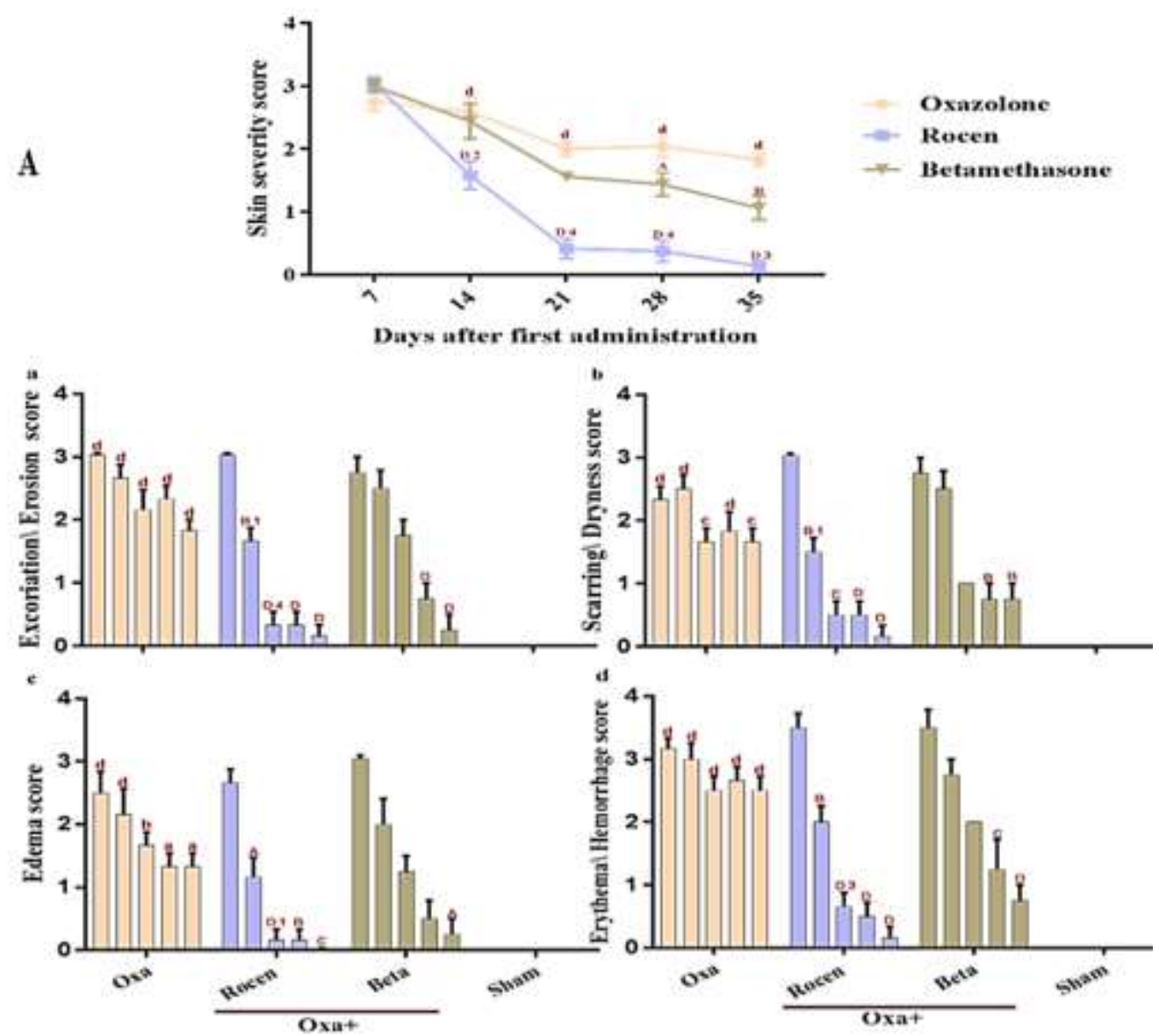

B

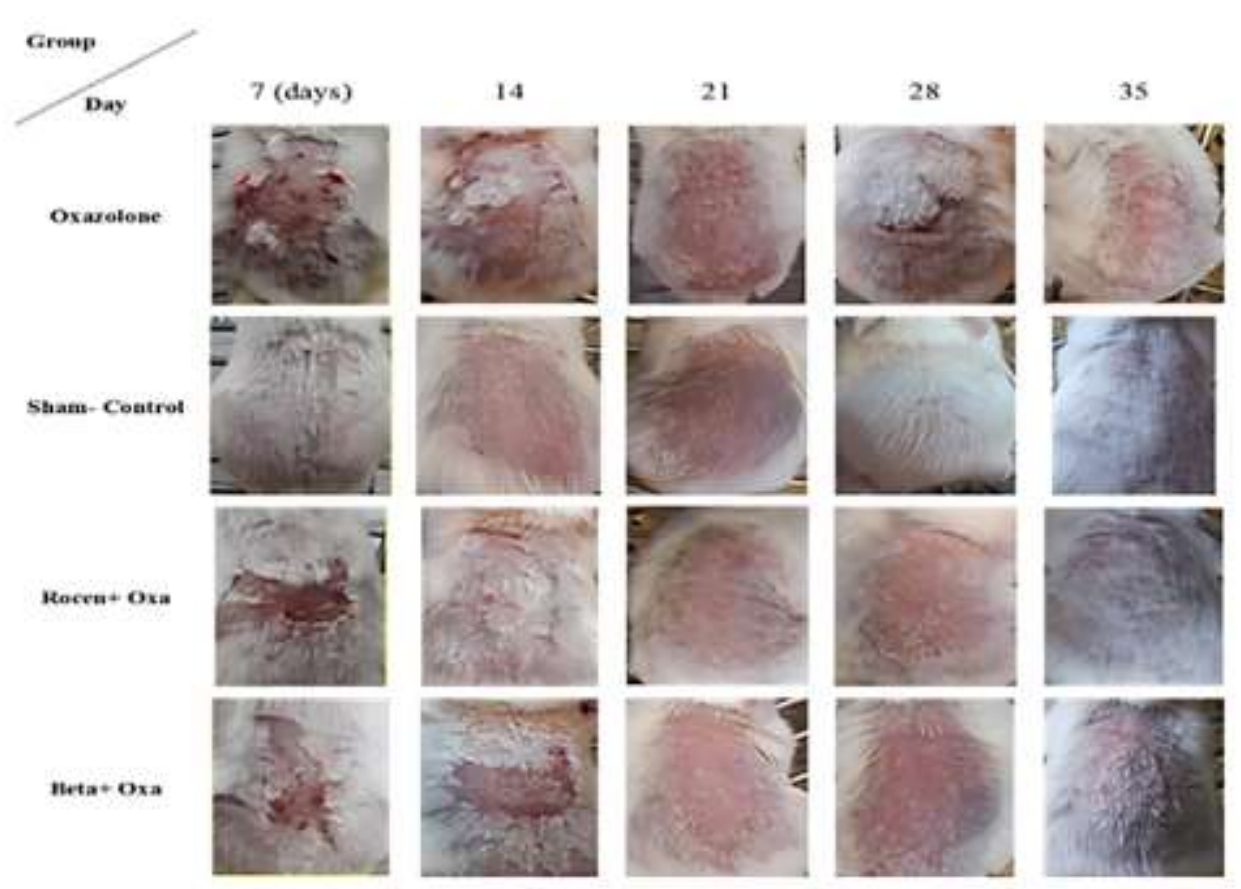

Figure 4: Indicative skin severity data of AD-like skin lesions treated by ROCEN in mice. A) skin severity scores indicate a significant dermatitis healing by topical ROCEN rather than Beta at relative time points. The severity score was achieved by the sum of the relative dermatitis data (a, b, c , and d scores) at each experiment and data represented by mean \pm SEM. B) Macroscopic features indicate that Oxa administration causes severe AD lesions at different time intervals while ROCEN and Beta treatments recover the lesion progress in mice. a, b, c, d: when Oxa group is compared with control group. A, B, C, D: treated groups are compared with Oxa group. 1, 2, 3, 4: ROCEN group is compared with Beta group. $\mathrm{Aa}^{1} ; \mathrm{p}<0.05, \mathrm{Bb}^{2} ; \mathrm{p}<0.01, \mathrm{Cc}^{3} ; \mathrm{p}<0.001, \mathrm{Dd}^{4} ; \mathrm{p}$ $<0.0001$. 

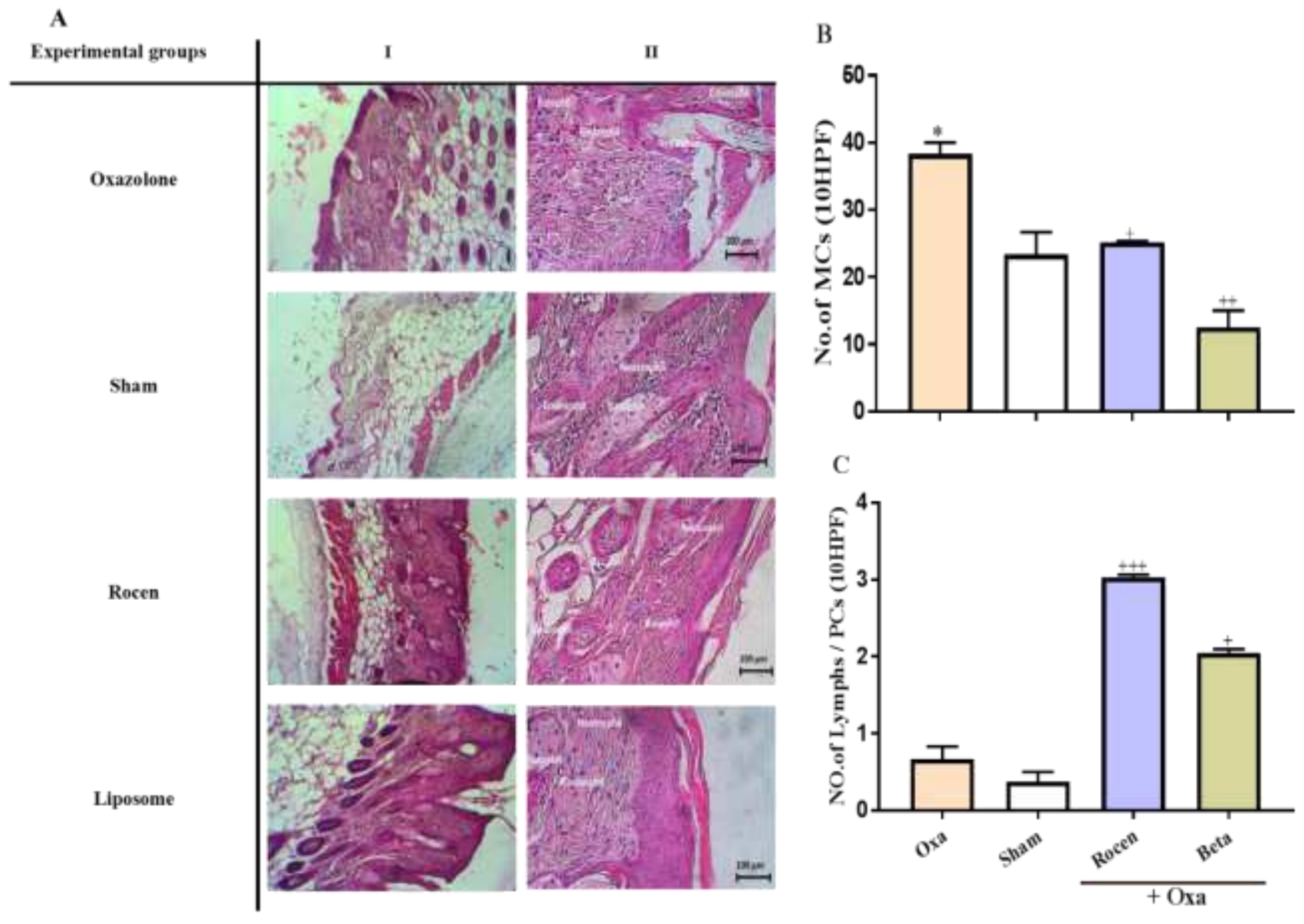

Figure 5: (A) I. Histopathological pictures of Oxa-induced chronic dermatitis and relative treated groups. II. The neutrophil, basophils, and eosinophil's cells were showed with a light microscope. B. The number of MCs and (C) Lymphs/ plasma cells were defined as the mean \pm SEM; $n=6$ for all groups. * When Oxa compared with sham group, and + treated group compared to Oxa group. $* \&,+; \mathrm{p}<0.05, * * *, \&,+++; \mathrm{p}<0.001$. 

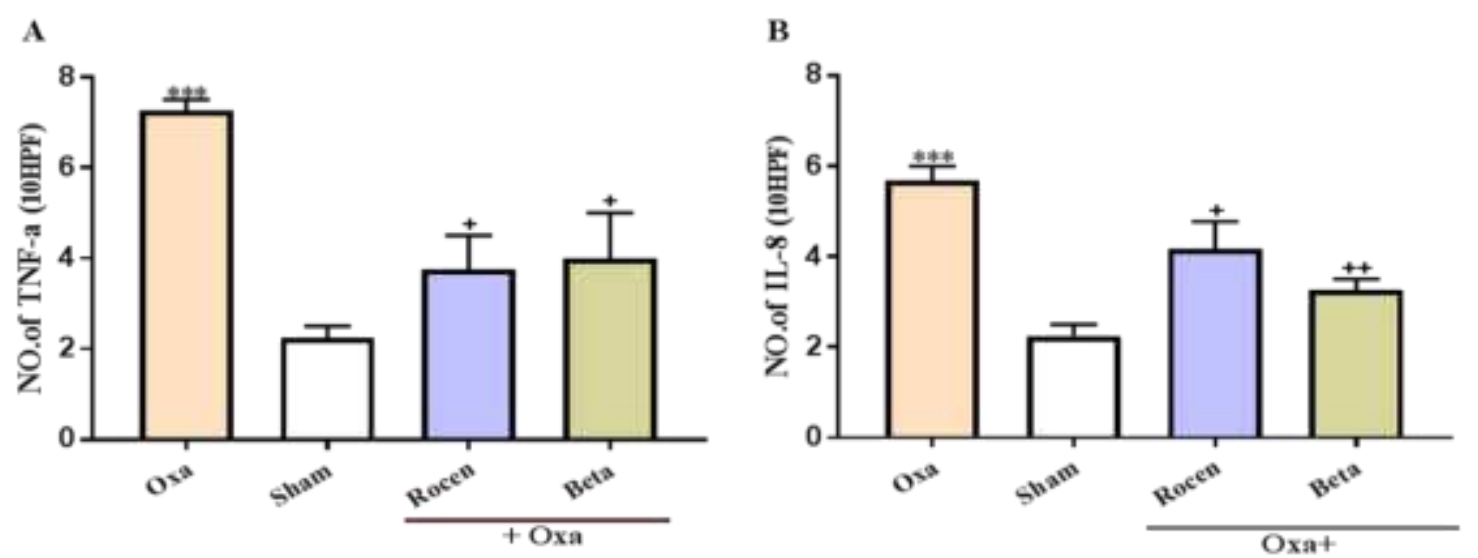

\section{Experimental \\ Groups}

Oxazolone

Sham

Rocen

Liposome

Betamethasone

IHC Factor

IL-8
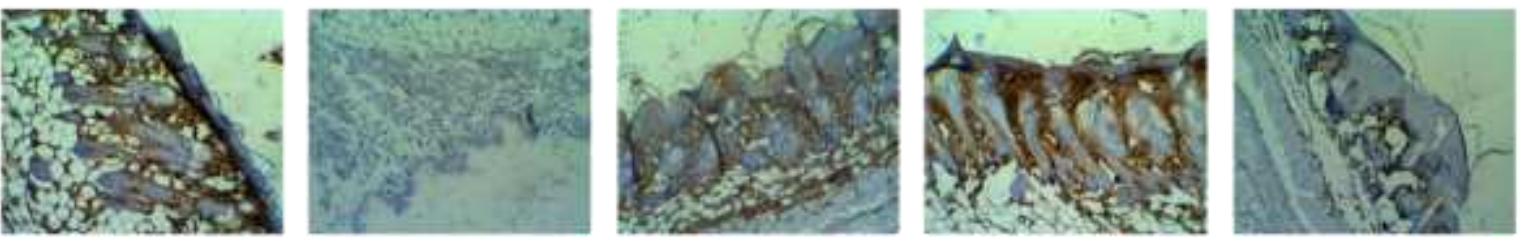

TNF-a
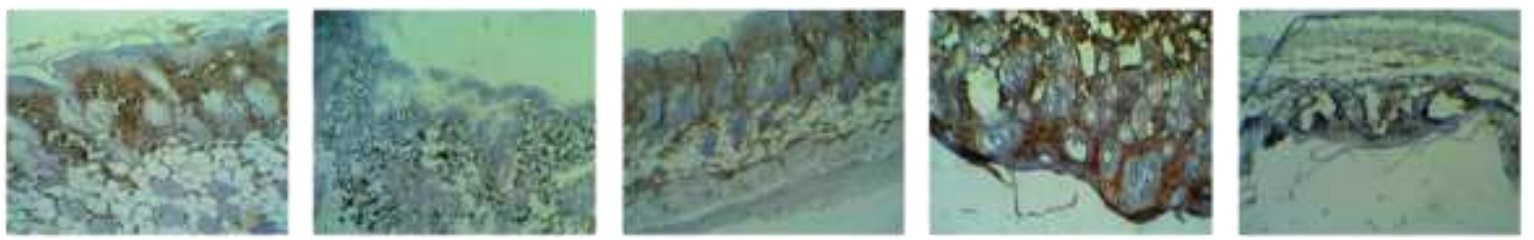

Figure 6: Data immunohistochemistry of cytokines related to topical treatment of AD. TNF- $\alpha$ (A) and IL-8 (B) analyzed by immunohistochemistry were defined as mean \pm SEM with $\mathrm{n}=6$. C) Photomicrograph of IHC section of the dorsal skin showing IL-8 and TNF-a. * Oxa compared with control group, + treated group compared with Oxa group (one-way ANOVA). * \& +; p $<0.05$, ** $\&++; \mathrm{p}<0.01$. 


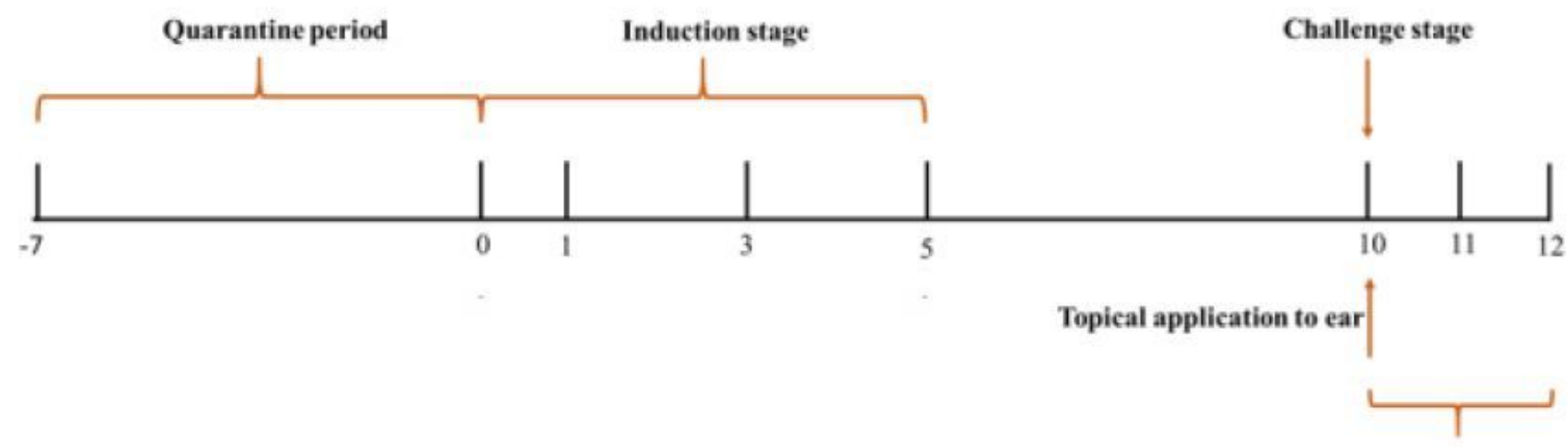

Ear thickness measurement

\section{Figure 1}

The line chart of the MEST protocol for allergenicity assessment.

Analysis of dermatitis behavior at days 7, 14, 21, 28, 35

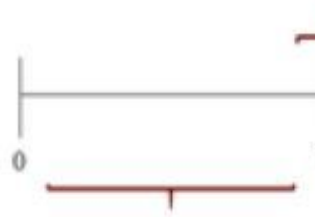

Oxa topical exposure ( $5 \%$ w/v in ethanol)

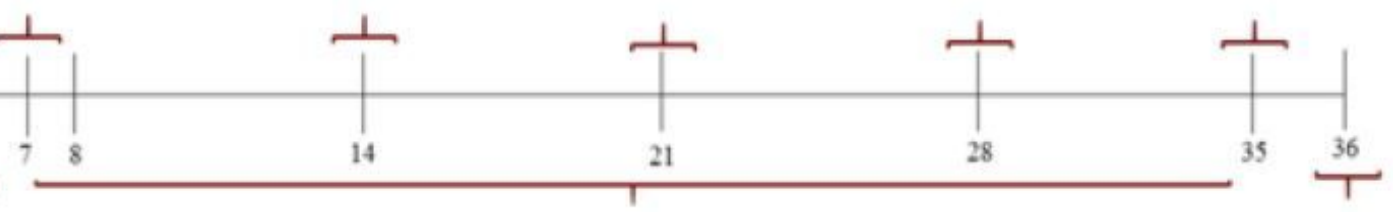

Oxa topical exposure $(0.5 \% \mathrm{w} / \mathrm{v}$ in ethanol) plus drug treatment
Histopathology and immunohistochemistry

\section{Figure 2}

Summary of experimental dermatitis protocol. 
$\Lambda$

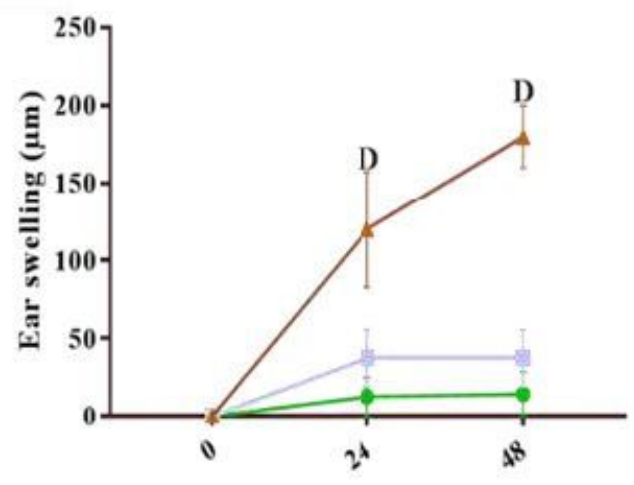

Time after challenge (Hours)

$\mathrm{C}$

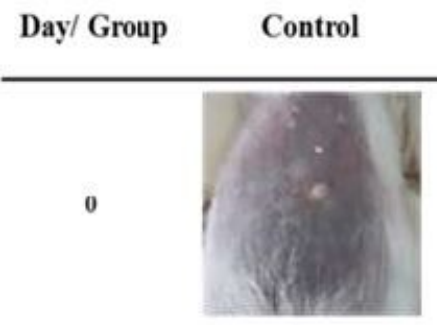

Rocen
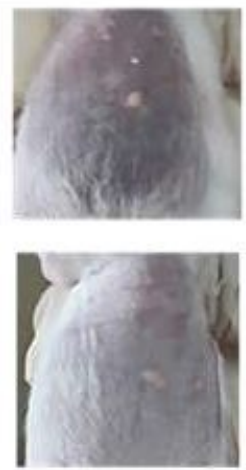

B

Day

12

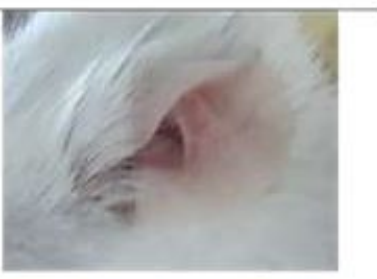

ROCEN

Ear swelling

Ear swelling

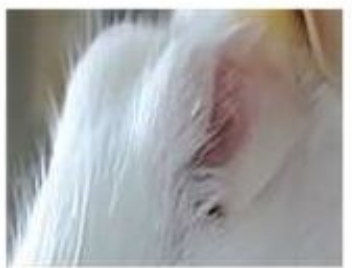

Formaldehyde

Ear swelling

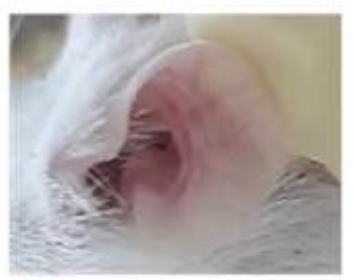

\section{Figure 3}

The demonstration of ROCEN sensitization evaluation using MEST. A. Swelling measurement of the left ear of the mice did not show any irritation via ROCEN application. $n=10$ for all groups. $D$ when treated groups compared with control group, (D; P-value $\otimes 0.0001)$. B. The representative mice ear shows a considerable ear redness in formaldehyde group (sensitized mice). C. The mice were shaved ventral abdomen on day 0 for induction of sensitization by applying two intradermal injections ( $40 \mu \mathrm{l})$ of adjuvant and $100 \mu \mathrm{l}$ of water (control), ROCEN, formaldehyde (as dermatitis lesion) were applied topically by rubbing gently. 

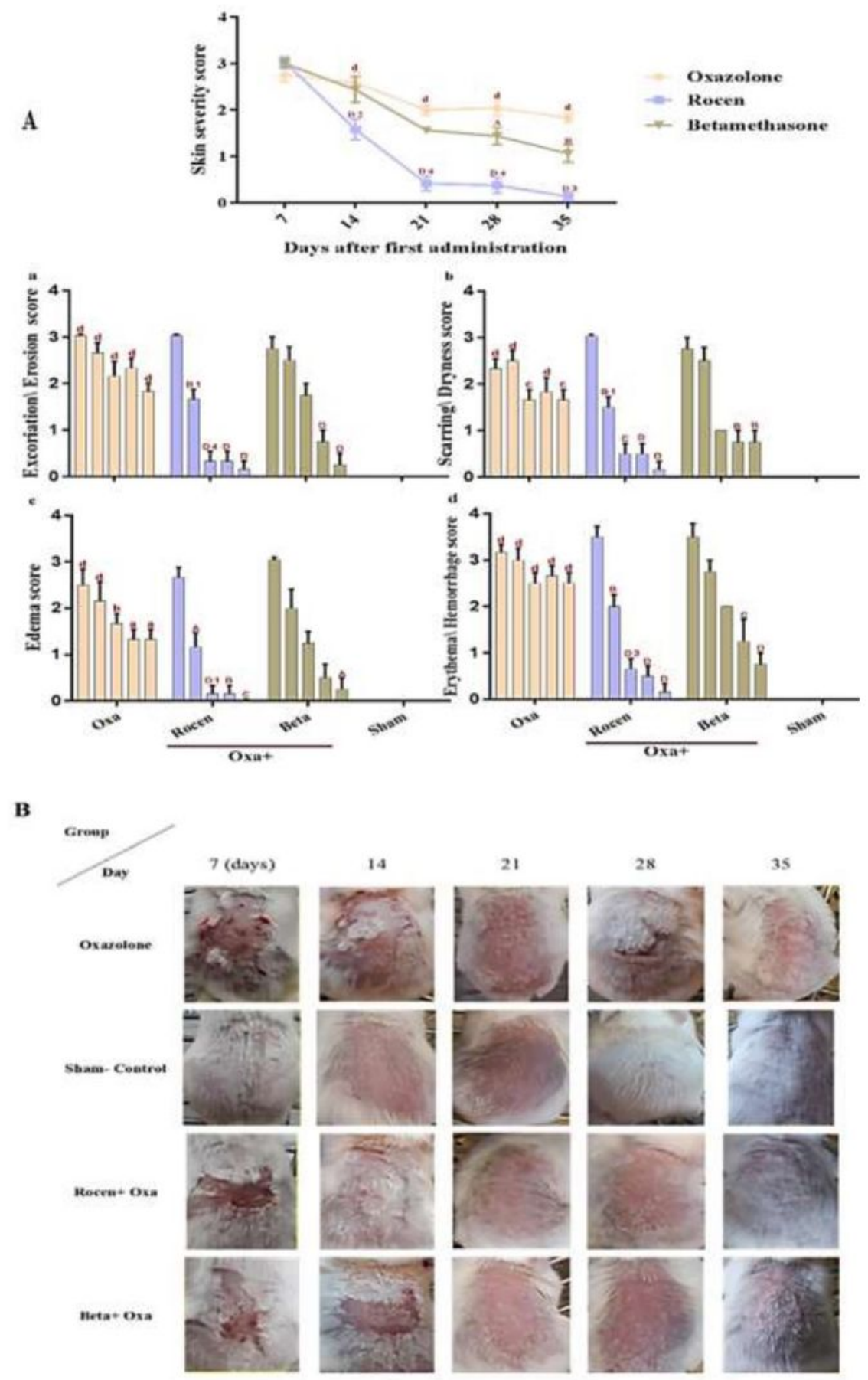

\section{Figure 4}

Indicative skin severity data of AD-like skin lesions treated by ROCEN in mice. A) skin severity scores indicate a significant dermatitis healing by topical ROCEN rather than Beta at relative time points. The severity score was achieved by the sum of the relative dermatitis data ( $a, b, c$, and d scores) at each experiment and data represented by mean \pm SEM. B) Macroscopic features indicate that $O x a$ administration causes severe AD lesions at different time intervals while ROCEN and Beta treatments 
recover the lesion progress in mice. $a, b, c$, d: when Oxa group is compared with control group. A, B, C, D: treated groups are compared with Oxa group. 1, 2, 3, 4: ROCEN group is compared with Beta group. Aa1; $p$ $\llbracket 0.05, \mathrm{Bb} 2 ; \mathrm{p} \otimes 0.01, \mathrm{Cc} 3 ; \mathrm{p} \rrbracket 0.001, \mathrm{Dd} 4 ; \mathrm{p} \rrbracket 0.0001$.
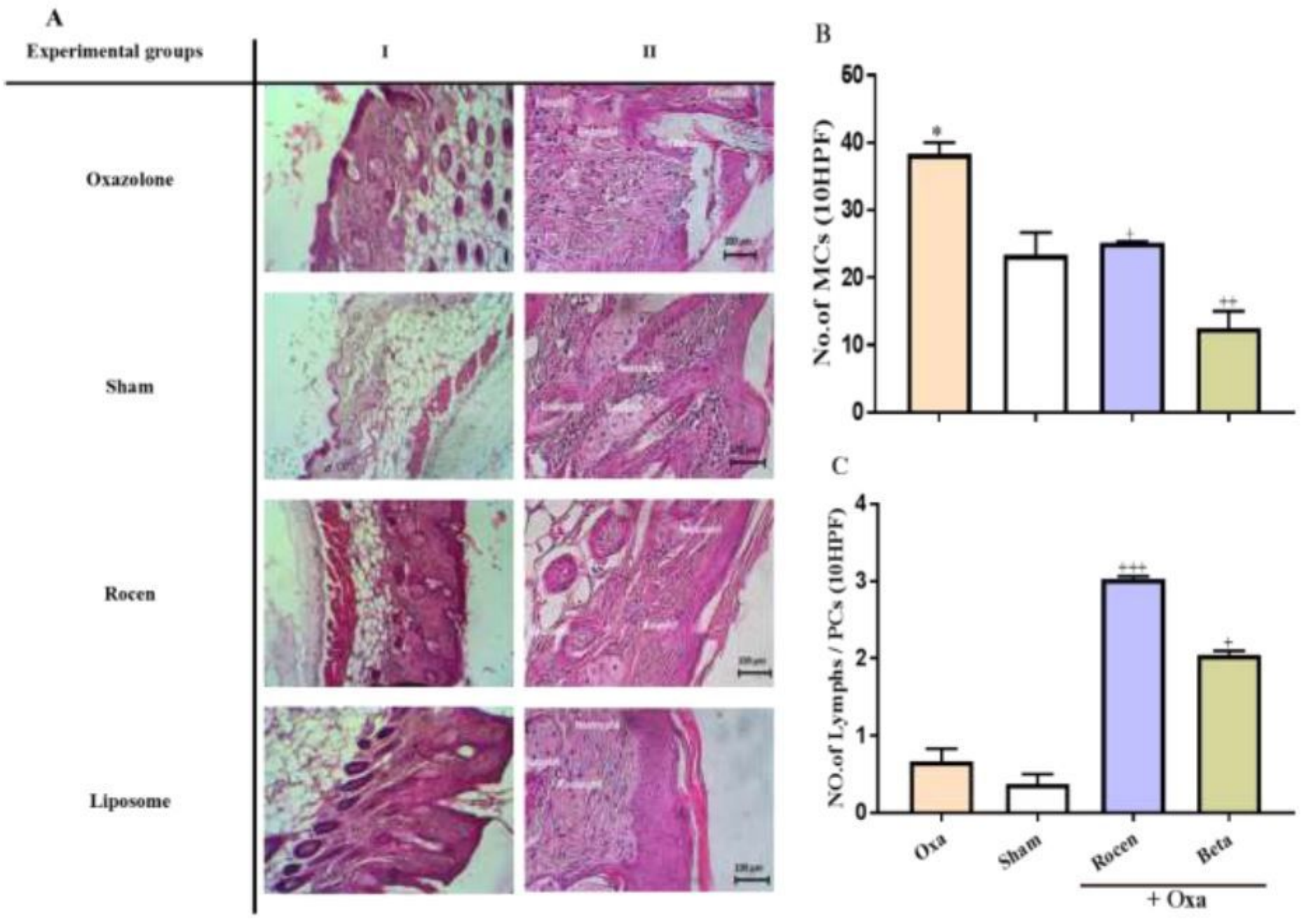

Figure 5

(A) I. Histopathological pictures of Oxa-induced chronic dermatitis and relative treated groups. II. The neutrophil, basophils, and eosinophil's cells were showed with a light microscope. B. The number of MCs and (C) Lymphs/ plasma cells were defined as the mean \pm SEM; $n=6$ for all groups. * When Oxa compared with sham group, and + treated group compared to Oxa group. $* \&,+; \mathrm{p} \rrbracket 0.05, \star \star \star, \&,+++; \mathrm{p} \rrbracket$ 0.001 . 
A

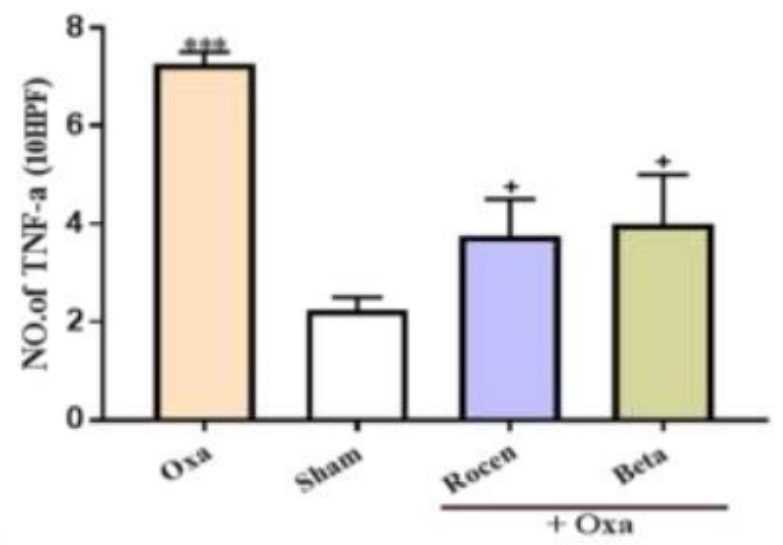

C

\section{Experimental \\ Groups}

I

IHC Factor

IL-8
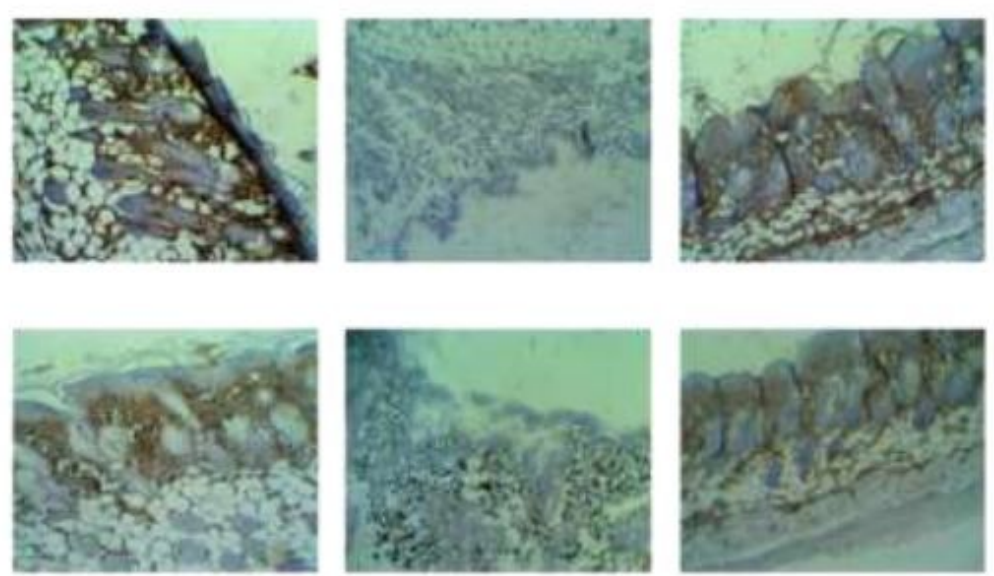

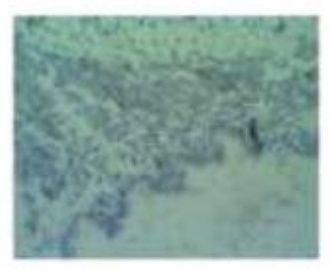

Sham

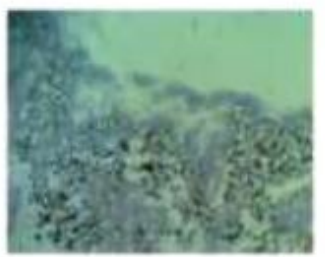

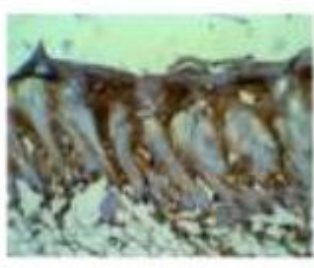

B

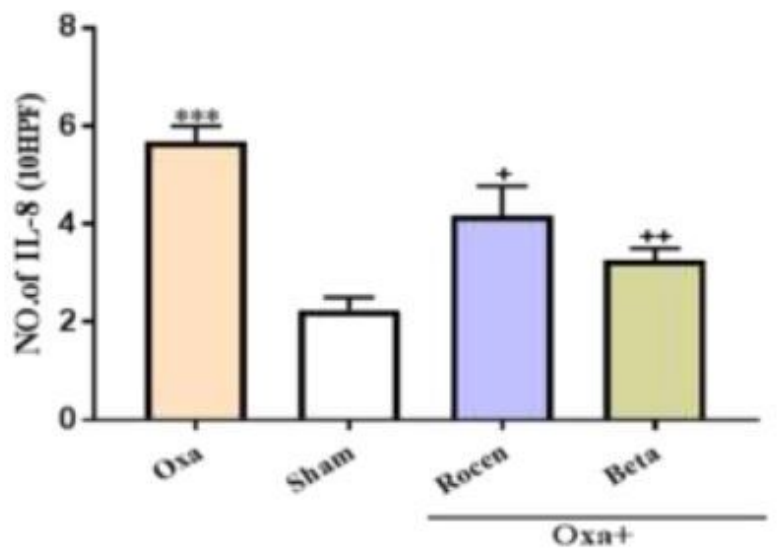

Rocen

Liposome

Betamethasone

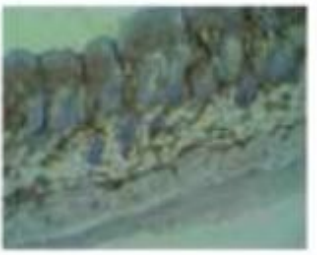

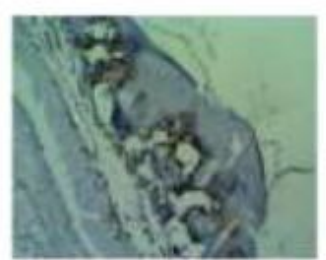

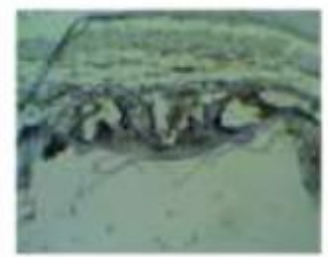

Figure 6

Data immunohistochemistry of cytokines related to topical treatment of AD. TNF-a (A) and IL-8 (B) analyzed by immunohistochemistry were defined as mean \pm SEM with $n=6$. C) Photomicrograph of $I H C$ section of the dorsal skin showing IL-8 and TNF-a. * Oxa compared with control group, + treated group

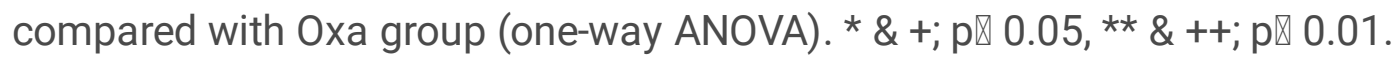

